\title{
CARBON DIOXIDE ELIMINATION DURING SPONTANEOUS VENTILATION WITH A MODIFIED MAPLESON D SYSTEM: STUDIES IN A LUNG MODEL
}

\author{
D.K. Rose, R.J. Byrick, AND A.B. Froese
}

THE RECENT ADOPTION of a modified Mapleson $\mathrm{D}$ (Bain) breathing system, ${ }^{1,2}$ as a "universal circuit", ${ }^{3}$ to be used during both spontaneous and controlled ventilation, has provoked renewed interest and confusion regarding the predictability of carbon dioxide tension in anaesthetized patients. Mapleson and others have shown that a fresh gas flow (FGF) rate of two to three times minute ventilation is required in such a circuit to prevent rebreathing in the spontaneously breathing patient. ${ }^{4,5}$ Any recommendation for the use of trimmed fresh gas flows (i.e. less than the Mapleson flows) which converts it to a rebreathing circuit, ${ }^{6}$ must be thoroughly evaluated to avoid inadvertent hypercapnia in anaesthetized patients.

The factors that determine the carbon dioxide tension in the alveoli (and hence in the blood) may be expressed by the following equations:

$$
\begin{aligned}
\mathrm{FACO}_{2}=\mathrm{FI}_{\mathrm{CO}_{2}}+\frac{\dot{\mathrm{VCO}_{2}}{ }^{7}}{\dot{\mathrm{V}}_{\mathrm{A}}} & \\
& =\mathrm{FJ}_{\mathrm{CO}_{2}}+\frac{\dot{\mathrm{V}} \mathrm{CO}_{2}}{\dot{\mathrm{V}}\left(1-\mathrm{VD}_{\mathrm{D}} / \mathrm{VT}\right)}
\end{aligned}
$$

Where $\mathrm{FACO}_{2}$ is the alveolar carbon dioxide fraction,

$\mathrm{FI}_{\mathrm{CO}_{2}}$ is the inspired carbon dioxide fraction,

$\dot{\mathrm{V}} \mathrm{CO}_{2}$ is $\mathrm{CO}_{2}$ production in $\mathrm{ml} / \mathrm{min}$,

$\dot{V}_{\mathrm{A}}$ is minute alveolar ventilation in $\mathrm{ml} / \mathrm{min}$,

$\dot{V}_{E}$ is total minute ventilation in $\mathrm{ml} / \mathrm{min}$

D.K. Rose, M.D., Research Fellow, Department of Anaesthesia, University of Toronto, Hospital for Sick Children, Toronto, Ont.

R.J. Byrick, M.D., F.R.C.P.(C). Department of Anaesthesia, University of Toronto, formerly at Hospital for Sick Children. now at St. Michael's Hospital, Toronto, Ontario.

A.B. Froese, M.D., F.R.C.P.(C). Department of Anaesthesia, University of Toronto, and Research Institute, Hospital for Sick Children, Toronto, Ontario.

Address for Reprints: Dr. A.B. Froese, Department of Respiratory Physiology, Hospital for Sick Children, 555 University Avenue, Toronto, M5G IX8.

\author{
$\mathrm{VD} / \mathrm{Vr}$ is ratio of effective dead-space \\ (which during anaesthesia is a \\ combination of apparatus, ana- \\ tomical \& alveolar dead-space) to \\ tidal volume.
}

The predictability of carbon dioxide tension in a patient depends on the predictability of the values in equation 1 . In the spontaneously breathing, anaesthetized patient, several of these values are highly variable and not specifically known to the anaesthetist (Table I). The $\dot{V} \mathrm{E}$, physiological dead space and $\mathrm{VCO}_{2}$ will directly alter the $\mathrm{FA}_{\mathrm{CO}_{2}}$. Variation in carbon dioxide responsiveness related to anaesthetic depth, surgical stimulation and differences between individuals will affect the patient's minute ventilation. Harrison has shown that the respiratory wave form, which varies markedly during spontaneous ventilation under anaesthesia, changes the fresh gas flow requirements to prevent rebreathing ${ }^{8}$ (i.e. influences $\mathrm{FI}_{\mathrm{CO}_{2}}$ ). Only the circuit variables (Table I) are firmly under the anaesthetist's control. If one decides to use a modified Mapleson D circuit with spontaneous respiration, a crucial decision about fresh gas flow requirement must be made. Recommendations in the literature range from the high flows of Mapleson (i.e. a non-rebreathing system $)^{4.5}$ down to values of 100 $\mathrm{ml} / \mathrm{kg} / \mathrm{min}$ (i.e. a variable rebreathing system) as recommended by Bain and Spoerel. ${ }^{9}$ Such major differences in circuit operation must have serious implications with respect to the maintenance of safe gas exchange in an unpredictably variable patient population.

This study was undertaken to determine the interaction of different fresh gas flow rates with the important respiratory variables of $\mathrm{VE}_{\mathrm{E}}, \mathrm{VD}_{\mathrm{D}} \mathrm{VT}$ and respiratory wave form at a constant $\dot{\mathrm{VCO}}_{2}$ using a modified Mapleson D circuit with spontaneous ventilation. Relevant reference levels were established using the standard Magill and Mapleson E circuits during spontaneous ventilation and the modified Mapleson D during controlled ventilation. Since it is impossible to assess and control all the relevant variables in anaesthetized subjects, investigations were carried out 
TABLE I

\begin{tabular}{|c|c|}
\hline Patient variables & Circuit variables \\
\hline $\begin{array}{l}\text { 1. Minute ventilation } \\
\text { 2. Physiological dead space } \\
\text { 3. } \mathrm{CO}_{2} \text { production } \\
\text { 4. } \mathrm{CO}_{2} \text { responsiveness } \\
\text { level of anaesthesia } \\
\text { degree of surgical stimulation } \\
\text { 5. Respiratory waveform }\end{array}$ & $\begin{array}{l}\text { 1. Fresh gas flow } \\
\text { 2. Apparatus dead space } \\
\text { mask } \\
\text { tracheal tube } \\
\text { 3. T-piece configuration } \\
\text { inlet of fresh gas } \\
\text { outlet of vented gas }\end{array}$ \\
\hline
\end{tabular}

using a model lung where the influence of each individual variable could be evaluated.

\section{METHOD}

A bag-in-bottle lung model (Figure 1) was constructed using a five litre high compliance bag impermeable to carbon dioxide inside an air-tight glass container. Carbon dioxide (ATPD) was accurately metered into the base of the "lung" and mixed with a small fan. Effective dead-space was varied by adding appropriate lengths of plastic tubing to the lung. Fresh gas (air) was supplied from a calibrated flow-meter (ATPD). Several circuits were used: the $\mathrm{T}$-piece with expiratory tubing long enough to prevent air dilution and an open-tailed bag (Jackson-Rees), a Bain circuit both with and without a spring-loaded pop-off valve (Heidbrink) and a three-litre reservoir bag attached at the end distal from the lung, and a Mapleson A (Magill) circuit. During spontaneous ventilation a sine wave ventilator (Harvard Pump) attached to the glass container expanded and contracted the "lung". With no circuit attached during spontaneous ventilation the "lung" simply drew in fresh room air (i.e. nonrebreathing system). An Air Shields constant volume ventilator was attached to the circuit for controlled ventilation.

Flow was measured by a Fleisch pneumotachograph of a size appropriate for all flows recorded (\#1). Volume (ATPD) was automatically integrated and recorded on a Watanabee 4-channel multiple speed recorder. Frequency and minute volume were measured on the tracing. Inspired and expired carbon dioxide levels were measured with the Medspect mass spectrometer calibrated with three known mixtures of carbon dioxide and air. End-tidal carbon dioxide in the model is equivalent to alveolar carbon dioxide and hence "arterial carbon dioxide" because perfect mixing was shown to occur in the model lung. The effective dead-space, i.e. the volume of the system that does not participate in carbon dioxide elimination, ordinarily includes contributions from alveolar, anatomical and apparatus dead-space. In the model, all of these were replaced by a length of plastic tubing, the volume of which was determined by water displacement. To see if this tubing does, in fact, function as the effective dead-space for the model, dead-space was measured on the model using the Bohr equation. ${ }^{10}$ This measurement was numerically equivalent to the volume of plastic tubing as determined by water displacement.

For the spontaneous mode minute volume, fresh gas flow, Vo/VT ratio, and circuit were varied but the inspiratory:expiratory ratio ( $\mathrm{I}: \mathrm{E}=$ $1: 1)$ frequency $(30)$ and carbon dioxide production $(180 \mathrm{ml} / \mathrm{min})$ were constant. These values simulate a $70 \mathrm{~kg}$ adult under light halothane anaesthesia. Future references to the model should be interpreted as applying to an average male patient. During mechanical ventilation with the Bain circuit, minute volume and fresh gas flow were varied but the $I: E$ ratio ( $1: 2)$, frequency (12) carbon dioxide production $(180 \mathrm{ml} / \mathrm{min})$ and $V_{D} / V_{T}$ ratio $(0.4)$ were constant.

The efficiency of different circuits is here defined as the fraction of the fresh gas delivered to the lung which clears carbon dioxide. This fractional utilization of fresh gas was calculated from the formula:

$$
\begin{aligned}
& f=\frac{\dot{V} \mathrm{CO}_{2}}{\mathrm{FGF} \times \mathrm{FACO}_{2}} \text { equation } 2 \text { (Conway' ') } \\
& \text { where } f=\text { fractional utilization of fresh gas } \\
& \dot{\mathrm{VCO}}_{2}=\text { carbon dioxide production in } \\
& \mathrm{ml} / \mathrm{min} \text {, } \\
& \text { FGF }=\text { fresh gas flow in } \mathrm{ml} / \mathrm{min} \text {, } \\
& \mathrm{FA}_{\mathrm{CO}_{2}}=\text { fractional concentration of car- }
\end{aligned}
$$

\section{RESULTS}

With spontaneous ventilation using room air and no added circuit, the model achieved end tidal carbon dioxide concentrations similar to 


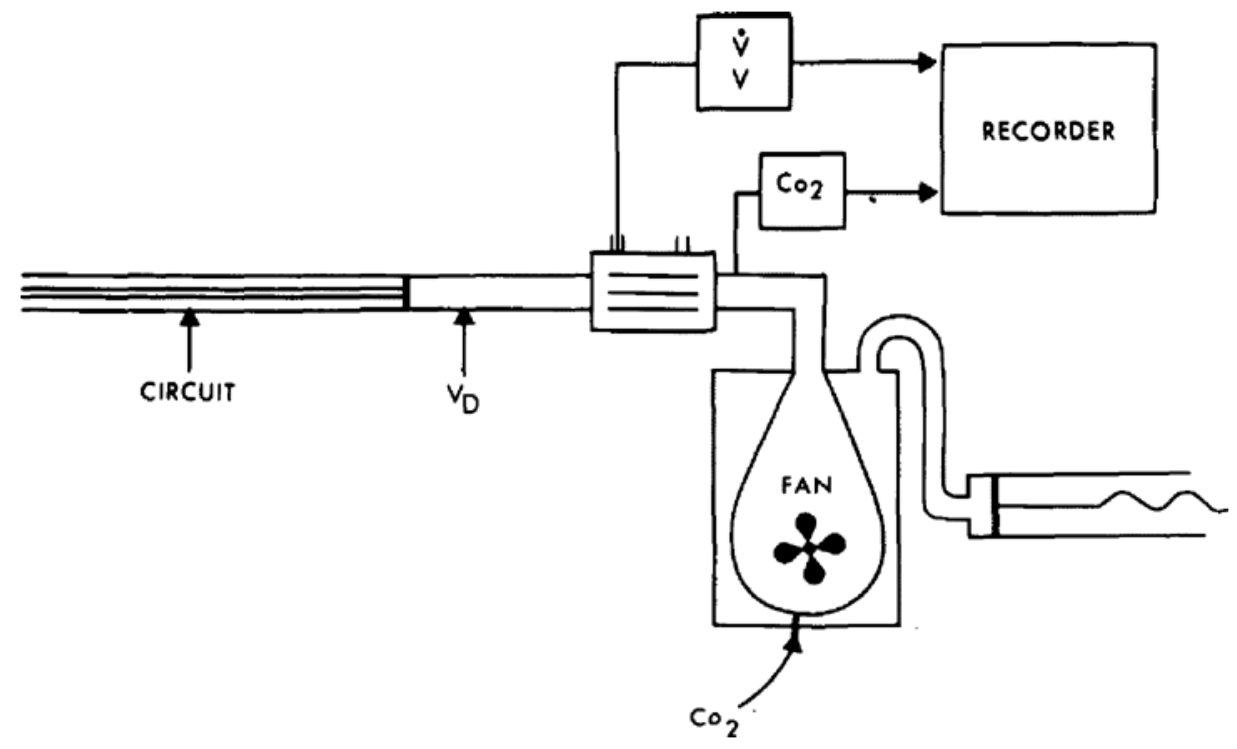

FIGURE 1. A compliant bag in a gas tight box served as the lung in the thorax. Controlled amounts of carbon dioxide were metered into the "lung" and mixed with a fan. To mimic "spontaneous ventilation" a Harvard pump attached to the "box" created a sinusoidal change of pressure around the "lung" to expand and contract it. For mechanical ventilation a Ventimeter ventilator was attached to the anaesthetic circuit (not shown). Dead space tubing ( $\left.V_{D}\right)$, the anaesthetic circuit, and the fresh gas flow (air flowmeter) were attached to the lung. Gas for carbon dioxide analysis by mass spectrometer was sampled near the junction of dead-space and alveolar compartments. A pneumotachograph was used for flow and volume measurements. All values were recorded on a polygraph.

values calculated from the formula $\mathrm{FACO}_{2}=$ $\dot{\mathrm{V}} \mathrm{CO}_{2} / \dot{\mathrm{V}}_{\mathrm{A}}$ (equation 1) for a non-rebreathing circuit (Figure 2) $\left(\mathrm{VD} / \mathrm{VT}=0.4, \dot{\mathrm{V}} \mathrm{CO}_{2}=180 \mathrm{ml} / \mathrm{min}\right.$, frequency $=30$ ).

Mechanical ventilation with a Bain circuit at two fresh gas flows is shown in Figure 3. (VD/VT $=0.4, \dot{\mathrm{V}}_{\mathrm{CO}_{2}}=180 \mathrm{ml} / \mathrm{min}$, frequency $=12$.) For a minute volume of 8.4 litres per minute, i.e. tidal volume $700 \mathrm{cc}(10 \mathrm{ml} / \mathrm{kg})$ and frequency of 12 per minute, the model's end-tidal carbon dioxide was 37 torr $(4.92 \mathrm{kPa})$ with the fresh gas flow set at 70 $\mathrm{ml} / \mathrm{kg} / \mathrm{min}(4.9 \mathrm{l} / \mathrm{min})$. Increasing the fresh gas flow to $100 \mathrm{ml} / \mathrm{kg} / \mathrm{min}(7 \mathrm{l} / \mathrm{min})$ reduced the endtidal carbon dioxide to 30 torr $(3.99 \mathrm{kPa})$. Above 8.4 litres minute ventilation, end-tidal carbon dioxide approached a plateau and was insensitive to further changes in $\dot{V} E$.

There was no difference in carbon dioxide concentrations using the Bain circuit with or without a Heidbrink valve. Data that follows has been obtained with no Heidbrink valve in place. Also end-tidal carbon dioxide concentrations during spontaneous ventilation from 3 to 10 litres minute ventilation were similar using an Ayre's T-piece and a Bain circuit at equal fresh gas flows (100 $\mathrm{ml} / \mathrm{kg} / \mathrm{min}$ ) (Figure 4), (VD $/ \mathrm{VT}=0.4, \dot{\mathrm{V}} \mathrm{CO}_{2}=180$ $\mathrm{ml} / \mathrm{min}$, frequency $=30$ ).

Both the Ayre's T-piece (FGF $=2.5 \times \dot{V} E)$ and a Magill circuit (FGF $=\dot{V}_{E}$ ) used with recom- mended fresh gas flows are essentially nonrebreathing systems during spontaneous ventilation $(\mathrm{VD} / \mathrm{VT}=0.4, \dot{\mathrm{VCO}}=180 \mathrm{ml} / \mathrm{min}$, frequency $=30$ ) (Figure 5). This was true from 3 to 12 litres/minute ventilation. Below four litres minute ventilation end-tidal carbon dioxide concentrations were above 55 torr $(7.32 \mathrm{kPa})$ with all circuits. Using the Bain circuit with $\dot{V}_{E}$ greater than $4 \mathrm{l} / \mathrm{min}$ (FGF $=100 \mathrm{ml} / \mathrm{kg} / \mathrm{min}$ ) values of end-tidal carbon dioxide were higher than those achieved by the two non-rebreathing circuits. The shaded area in Figure 5 reflects the increase in end-tidal carbon dioxide due to rebreathing at any given $\dot{V} E$ for the Bain circuit at this fresh gas flow rate. At six litres minute ventilation with a non-rebreathing circuit the end-tidal carbon dioxide was 38 torr ( $5.05 \mathrm{kPa}$ ), but the rebreathing which occurred with a Bain circuit at this fresh gas flow rate increased the end-tidal carbon dioxide to 47 torr (6.25 kPa). Only at 10 litres minute ventilation was an end-tidal carbon dioxide level of 40 torr $(5.32 \mathrm{kPa})$ achieved, this representing a 20 torr $(2.66 \mathrm{kPa})$ increase in endtidal carbon dioxide due to rebreathing. A plateau of end-tidal carbon dioxide was evident above a minute ventilation of 10 litres with the Bain circuit.

Changing the fresh gas flow delivered to a Bain circuit from $70 \mathrm{ml} / \mathrm{kg} / \mathrm{min}(4.9 \mathrm{1} / \mathrm{min})$ to 100 


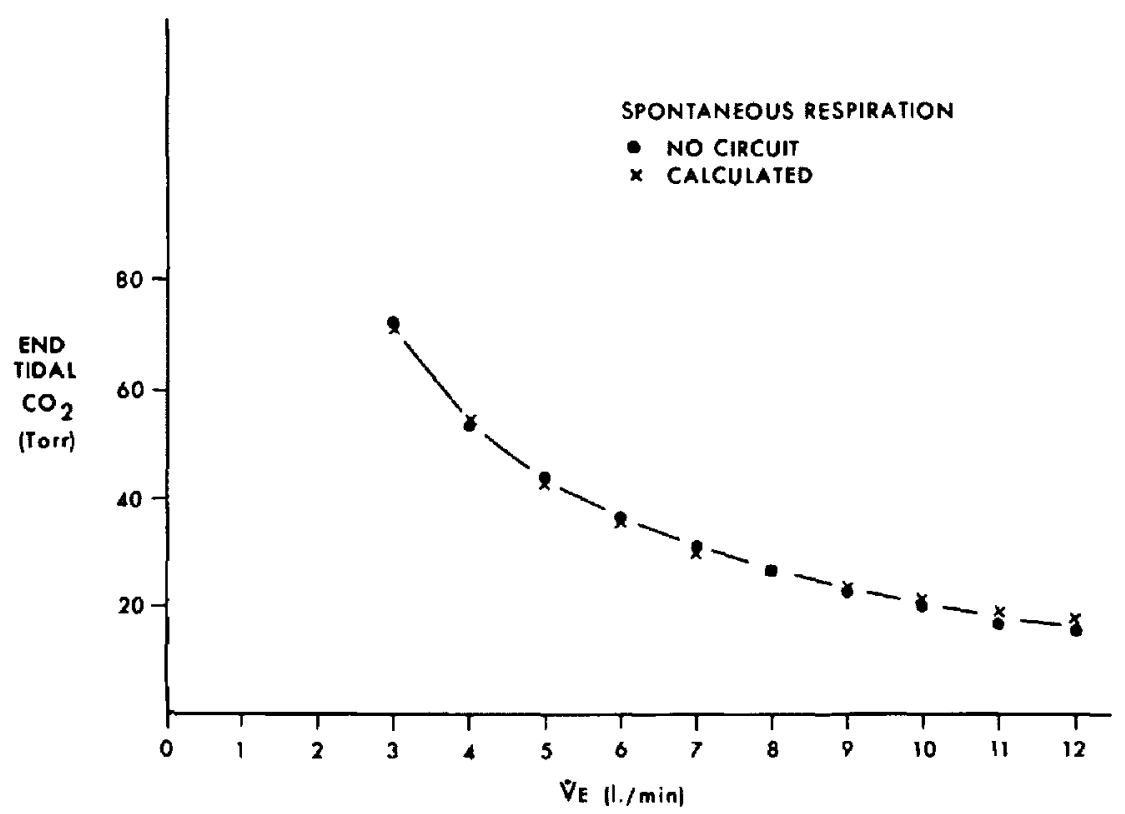

FiGure 2. Observed and calculated values for end-tidal carbon dioxide $\left(\mathrm{FA}_{\mathrm{CO}_{2}}=\dot{\mathrm{V}}_{\mathrm{CO}_{2}} / \mathrm{V}_{\mathrm{A}}\right)$ plotted against $\grave{V}_{\mathrm{E}}$ during spontaneous ventilation with a non-rebreathing system, using the lung model $\left(\dot{V} \mathrm{CO}_{2}=180 \mathrm{ml} / \mathrm{min} \mathrm{VD} / \mathrm{VT}=\right.$ 0.4).

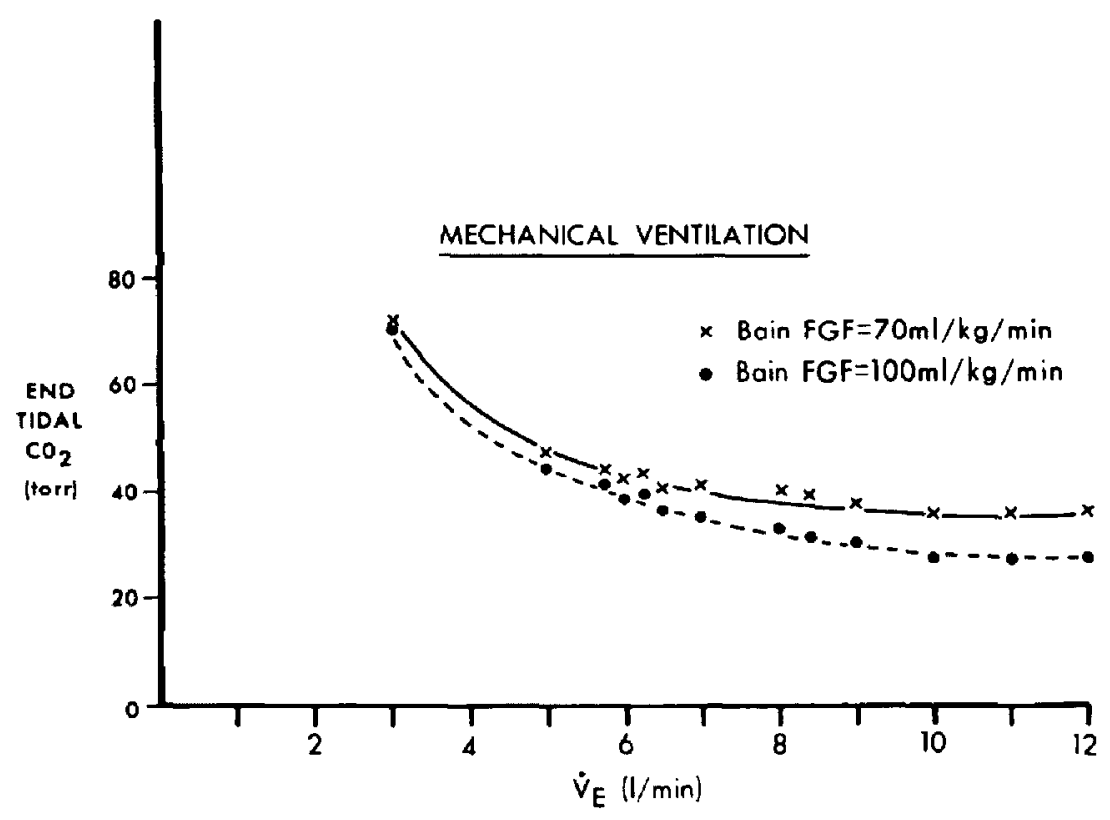

FIGURE 3. End-tidal carbon dioxide during controlled ventilation for different levels of minute ventilation at two fresh gas flows $\left(\mathrm{VCO}_{2}=180 \mathrm{ml} / \mathrm{min} \mathrm{Vo} / \mathrm{VT}_{\mathrm{T}}=0.4\right)$. 


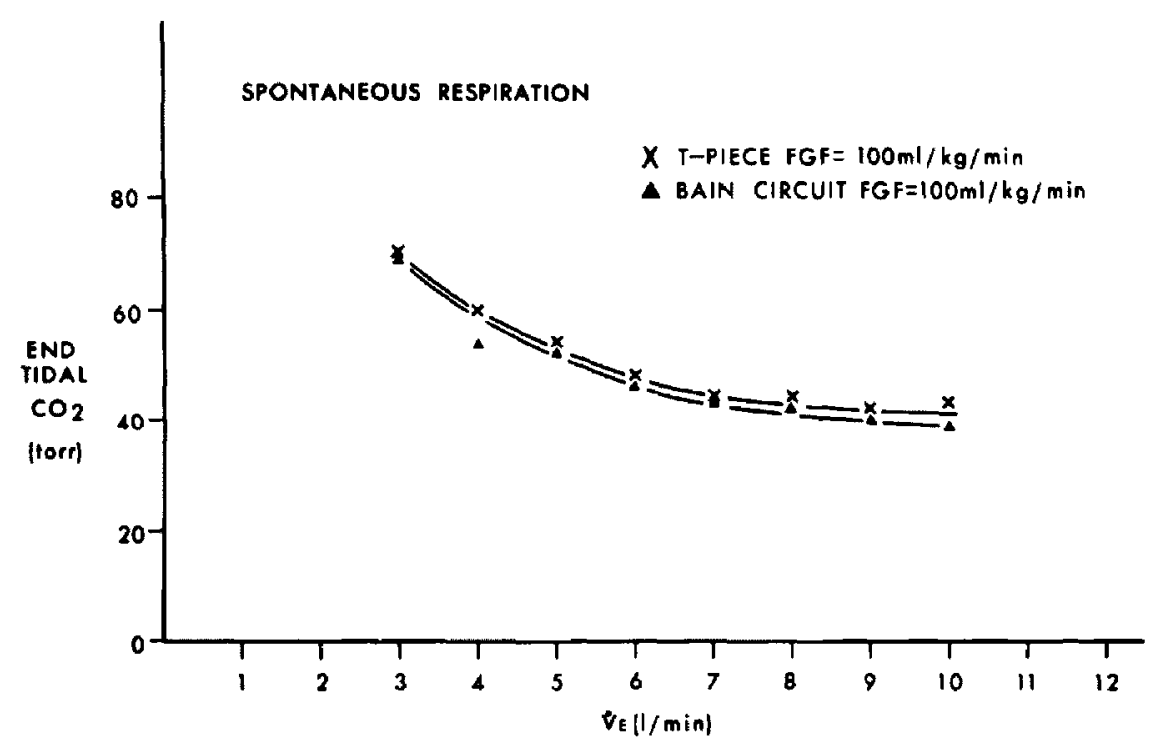

FIGURE 4. End-tidal carbon dioxide obtained with a Bain circuit and Ayre's T-piece using similar fresh gas flows $\left(F G F=100 \mathrm{ml} / \mathrm{kg} / \mathrm{min}, \dot{\mathrm{V} C O_{2}}=180 \mathrm{ml} / \mathrm{min} \mathrm{VD} / \mathrm{VT}=0.4\right)$.

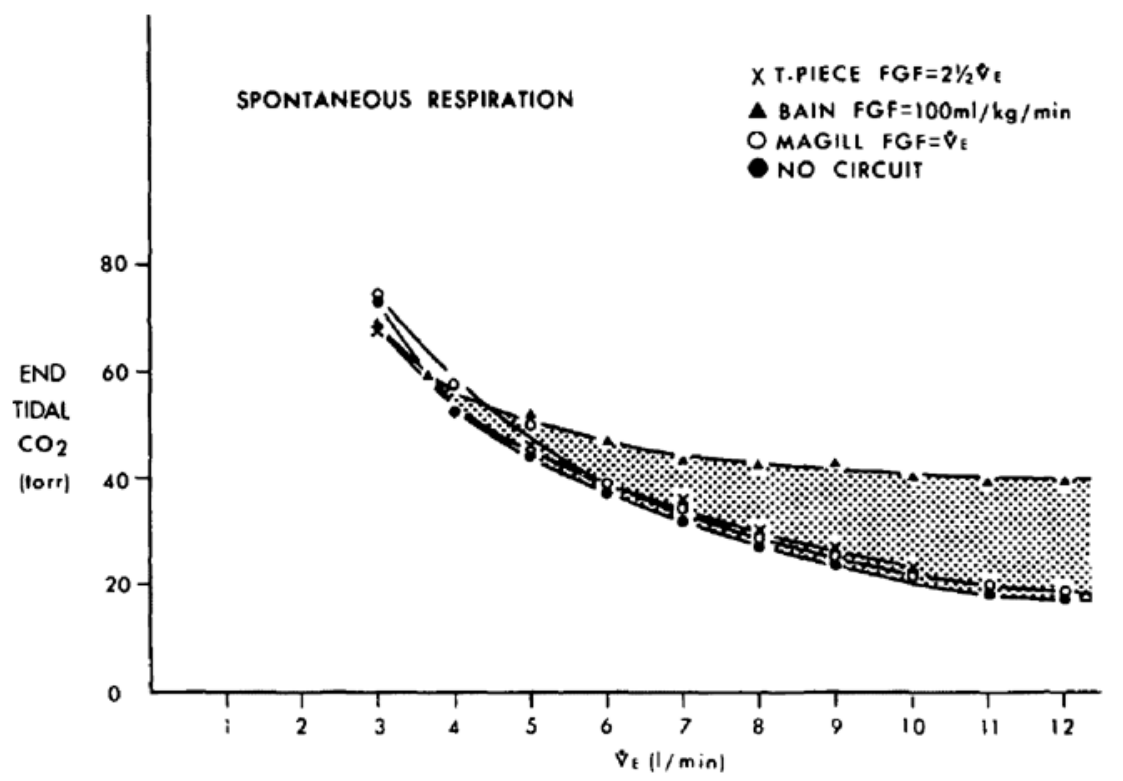

FIGURE 5. End-tidal carbon dioxide using the Bain, T-piece, Magill and a non-rebreathing system at different minute ventilations $\left(\dot{\mathrm{V}} \mathrm{CO}_{2}=180 \mathrm{ml} / \mathrm{min} \mathrm{VD} / \mathrm{VT}=0.4\right)$.

$\mathrm{ml} / \mathrm{kg} / \mathrm{min}(71 / \mathrm{min})$ to $140 \mathrm{ml} / \mathrm{kg} / \mathrm{min}(9.81 / \mathrm{min})$ decreased the end-tidal carbon dioxide concentrations $\left(\mathrm{VD} / \mathrm{VT}=0.4, \dot{\mathrm{VCO}_{2}}=180 \mathrm{ml} / \mathrm{kg} / \mathrm{min}\right.$, frequency $=30$ ) (Figure 6). However, below four litres minute ventilation end-tidal carbon dioxide levels were still above 55 torr $(7.32 \mathrm{kPa})$ at all three fresh gas flows. At 6 litres minute ventilation with fresh gas flow of $70 \mathrm{ml} / \mathrm{kg} / \mathrm{min}, 100$ $\mathrm{ml} / \mathrm{kg} / \mathrm{min}$, and $140 \mathrm{ml} / \mathrm{kg} / \mathrm{min}$ end-tidal carbon dioxide levels were 56 torr $(7.45 \mathrm{kPa})$ and 47 torr $(6.25 \mathrm{kPa})$ and 40 torr $(5.32 \mathrm{kPa})$ respectively. When minute ventilation was increased to 10 


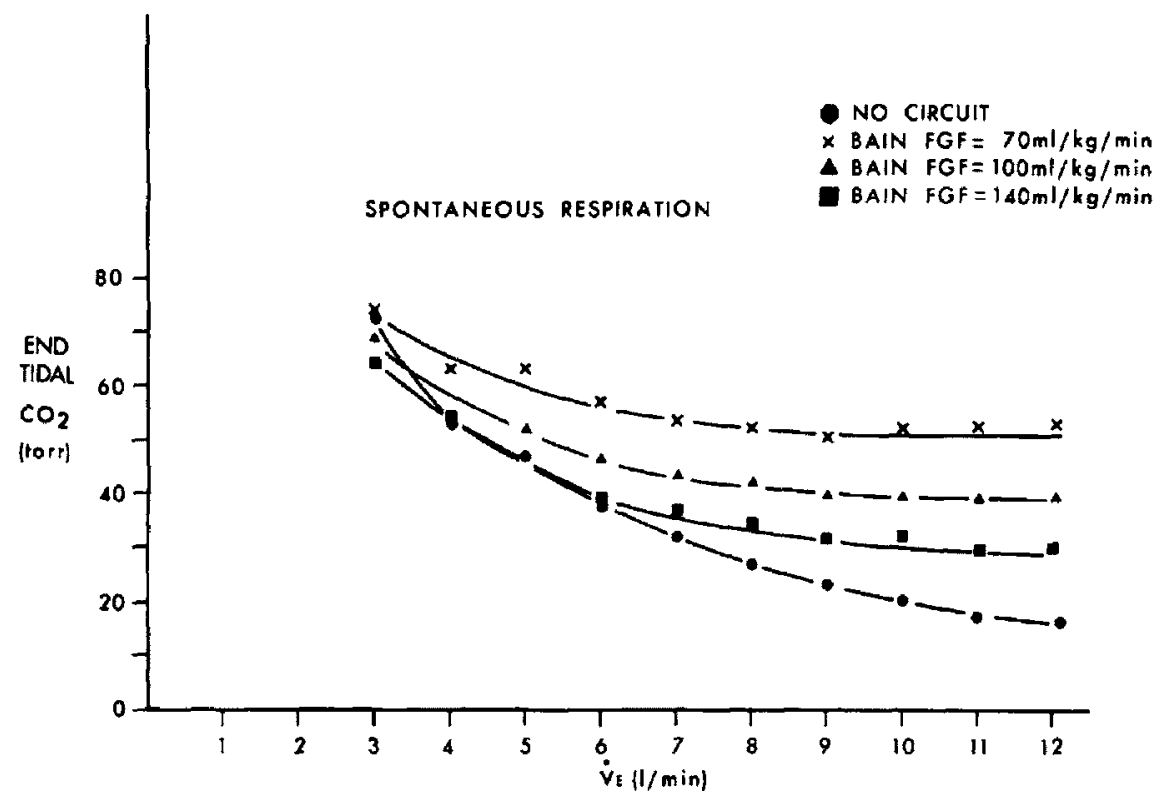

Figure 6. The effect of changing the fresh gas flows used with a Bain circuit on the relationship of end-tidal carbon dioxide to minute ventilation $\left(\dot{\mathrm{V}} \mathrm{CO}_{2}=180 \mathrm{ml} / \mathrm{min} \mathrm{VD}_{\mathrm{D}} / \mathrm{VT}_{\mathrm{T}}=0.4\right)$,

litres per minute using a fresh gas flow of 100 $\mathrm{ml} / \mathrm{kg} / \mathrm{min}(7 \mathrm{l} / \mathrm{min})$, end-tidal carbon dioxide decreased to 40 torr $(5.32 \mathrm{kPa})$. Despite an increase in minute ventilation to 12 litres for a fresh gas flow of $70 \mathrm{ml} / \mathrm{kg} / \mathrm{min}$, end-tidal carbon dioxide approached a plateau of 50 torr $(6.65 \mathrm{kPa})$.

When the effective dead space to tidal volume ratio was increased to 0.65 during spontaneous ventilation, the end-tidal carbon dioxide level with a Bain circuit was elevated to 70 torr $(9.31$ $\mathrm{kPa})$ at 6 litres $\dot{\mathrm{V}}_{\mathrm{E}}\left(\dot{\mathrm{V}} \mathrm{CO}_{2}=180 \mathrm{ml} / \mathrm{min}\right.$, frequency $=30), \mathrm{FGF}=100 \mathrm{ml} / \mathrm{kg} / \mathrm{min}$ ) (Figure 7). At 9 litres minute ventilation end-tidal carbon dioxide levels were 57 torr $(7.58 \mathrm{kPa})$ when a Bain was used and 40 torr $(5.32 \mathrm{kPa})$ when a nonrebreathing circuit was used. Despite an increase in $\dot{V} E$ to 12 litres end-tidal carbon dioxide remained elevated at 50 torr $(6.65 \mathrm{kPa})$ when the fresh gas flow was $100 \mathrm{ml} / \mathrm{kg} / \mathrm{min}$.

In Figure 8 the influence of fresh gas flow on end-tidal carbon dioxide is shown for $V_{D} / V_{T}$ 0.65 . Even with fresh gas flow at $140 \mathrm{ml} / \mathrm{kg} / \mathrm{min}$ and $\dot{V}_{E} 12$ litres, an end-tidal carbon dioxide of 40 torr $(5.32 \mathrm{kPa})$ was not achieved.

The fractional utilization of fresh gas flow (Figure 9) was 0.57 for the Magill circuit and constant at all levels of ventilation $\left(V_{D} / V_{T}=0.4\right.$, $\dot{\mathrm{V}} \mathrm{CO}_{2}=180 \mathrm{ml} / \mathrm{min}$, frequency $=30$ ) when fresh gas flow was equal to minute ventilation. For a Bain (FGF $=100 \mathrm{ml} / \mathrm{kg} / \mathrm{min}$ ) the fractional utilization was variable being 0.23 at low minute vol- umes and increasing to a maximum of 0.47 at 12 litres minute ventilation. When fresh gas flow in the Bain circuit was determined by minute ventilation and kept at $2.5 \times \dot{V} E$ then the fractional utilization of fresh gas dropped to 0.23 , but remained constant.

\section{Discussion}

It is evident from this study using a model lung that unpredictable degrees of hypercarbia can occur using a modified Mapleson D system during spontaneous ventilation at low fresh gas flow. The variability of the factors determining the extent of the hypercarbia as reproduced in this model is inherent in the patient and the anaesthetic state and is not an intrinsic property of the circuit. Therefore, this most recent modification of the Mapleson D circuit can in no way negate the influence of patient variables on gas exchange (Table I) during spontaneous respiration.

\section{VALIDATION OF THE MODEL}

The validity of the model used as a reflection of the circumstances present in patients must be discussed. Certain assumptions were necessary for its construction. The $\mathrm{VCO}_{2}$ was set at 180 $\mathrm{ml} / \mathrm{min}$ ATPD which is 90 per cent of basal metabolic rate for an adult. ${ }^{12}$ Only one level of carbon dioxide production was investigated since 


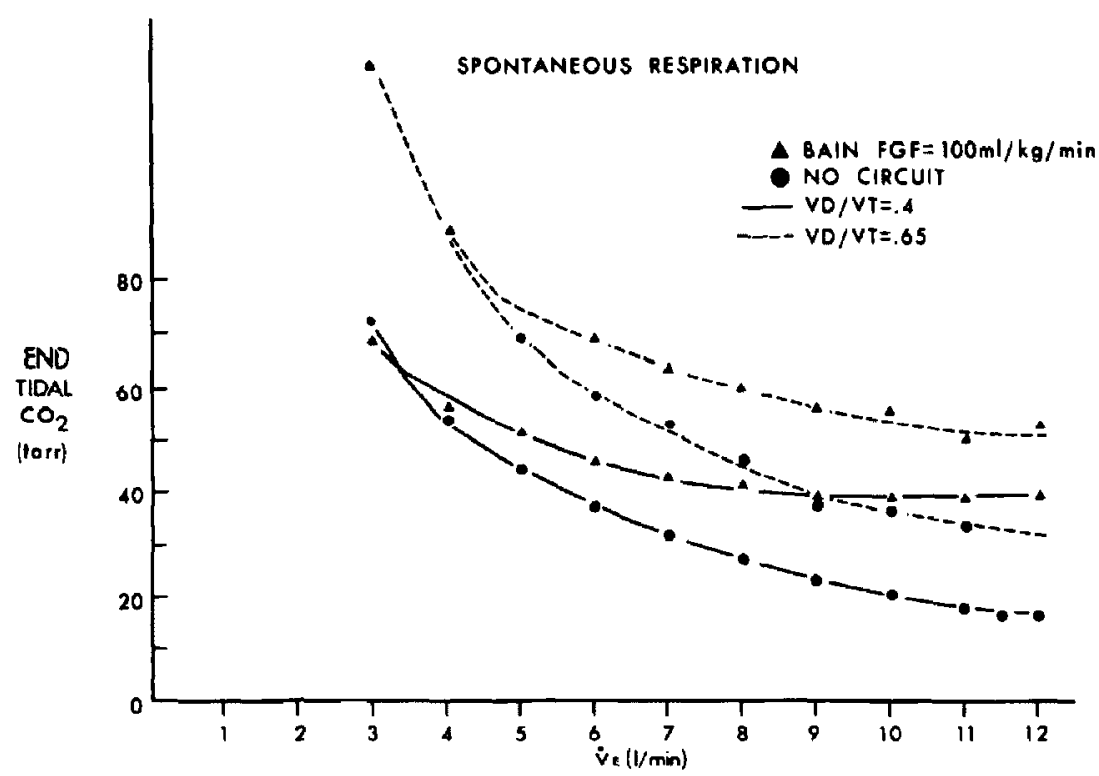

FIGURE 7. End-tidal carbon dioxide using a Bain circuit ( $F G F=100 \mathrm{ml} / \mathrm{kg} / \mathrm{min}$ ) and a non-rebreathing circuit with $\mathrm{VD} / \mathrm{VT} 0.4$ and 0.65 at different levels of minute ventilation $\left(\dot{V} \mathrm{CO}_{2}=180 \mathrm{ml} / \mathrm{min}\right)$.

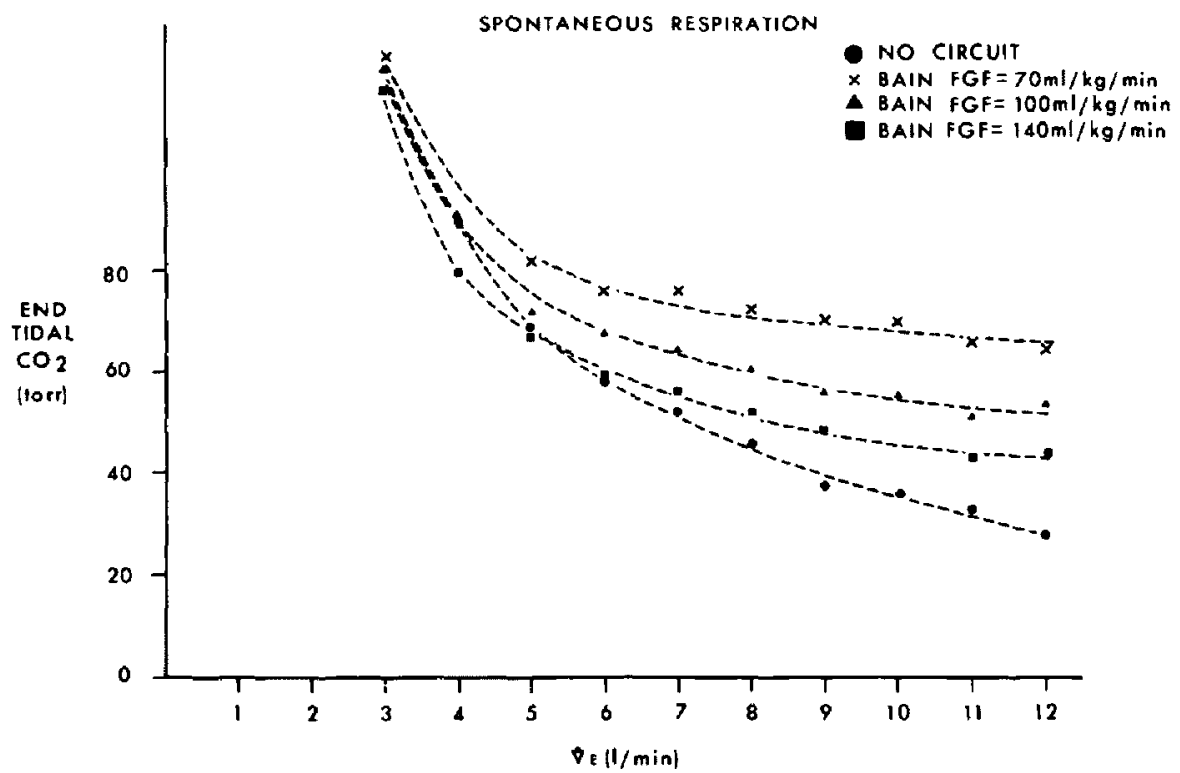

FIGURE 8. The effect of changing the fresh gas flows with a Bain circuit on the relationship of end-tidal carbon dioxide to minute ventilation $\left(\dot{\mathrm{V} C \mathrm{CO}_{2}}=180 \mathrm{ml} / \mathrm{min} \mathrm{VD} / \mathrm{VT}_{\mathrm{T}}=0.65\right)$.

any variation in $\mathrm{VCO}_{2}$ from this value will cause a simple proportional change in $\mathrm{Pa}_{\mathrm{CO}_{2}}$. Conditions such as fever, hyperthyroidism and sepsis can markedly increase $\mathrm{VCO}_{2}$ above this level. The impact of such increases has been clearly out- lined by Ramanathan, et al. ${ }^{13}$ and Keenan and Boynan ${ }^{14}$ in studies using mechanical ventilation. Two waveforms were used with the model lung; a sine wave with $\mathrm{I}: \mathrm{E}=1: 1$ for spontaneous ventilation (no pause), and a square wave with 


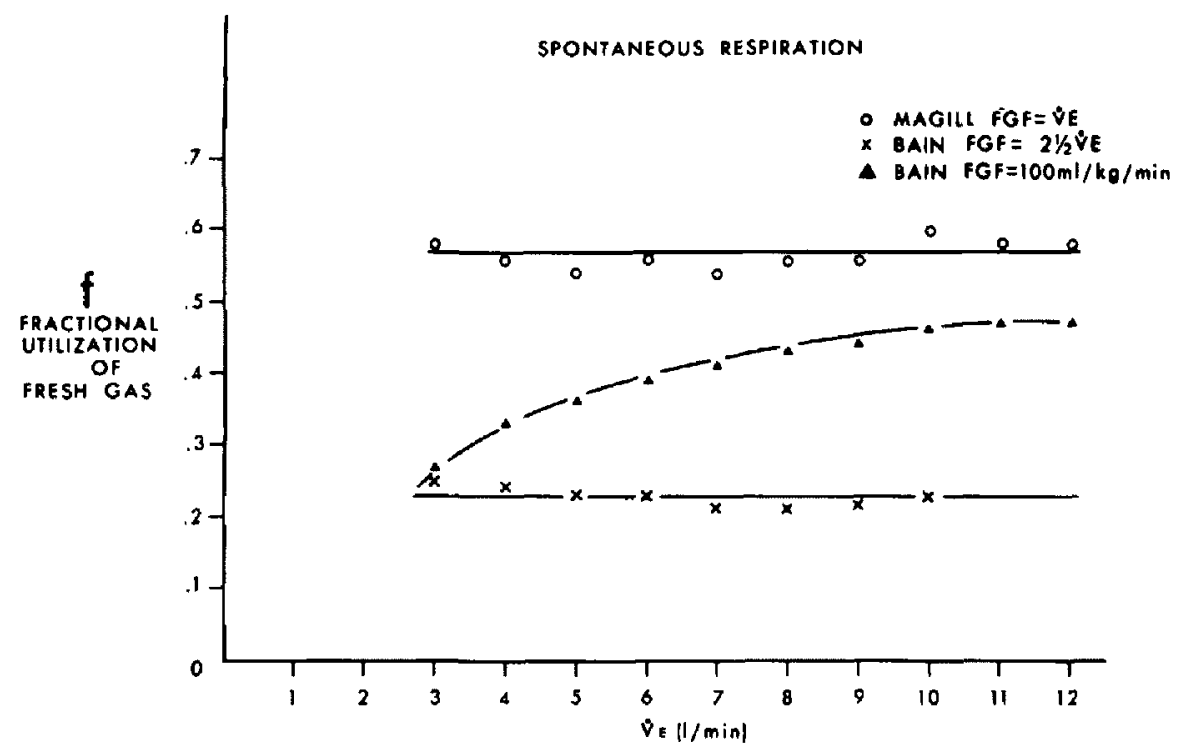

Fioure 9. Fractional utilization of fresh gas flow at different levels of minute ventilation with a Magill (FGF = $\dot{V} E), B$ ain $(F G F=100 \mathrm{ml} / \mathrm{kg} / \mathrm{min})$ and Bain $(\mathrm{FGF}=21 / 2 \times \dot{\mathrm{VE}})\left(\dot{\mathrm{V}} \mathrm{CO}_{2}=180 \mathrm{ml} / \mathrm{kg} / \mathrm{min} \mathrm{VD} / \mathrm{VT}=0.4\right)$.

$1: E=1: 2$ (i.e. long expiratory pause) for mechan. ical ventilation. It is well documented that respiratory wave form has a marked influence on the amount of fresh gas flow required to prevent rebreathing. Expiratory pauses facilitate washout of the expiratory limb by fresh gas. With lower peak inspiratory flows, less gas need be drawn from the expiratory limb to supplement fresh gas flow. ${ }^{4.8}$ A square wave with a long $\mathrm{ex}$ piratory pause is a very common pattern during mechanical ventilation. However, it is recognized that the respiratory wave form of anaesthetized patien.s breathing spontaneously varies widely with anaesthetic agent, depth and technique of administration. ${ }^{15}$ Nunn and Ezi-Ashi noted a trend for patients with low minute volumes to breathe with long $(>3 \mathrm{sec}$ ) expiratory pauses but as minute ventilation approached normal values, the expiratory pauses progressively shortened. When high minute ventilation was induced by rebreathing in a group of normal subjects the expiratory pause was abolished and the respiratory wave form became essentially a sine wave with equal inspiratory and expiratory periods $(\mathrm{I}: \mathrm{E}=1: 1)$ and flow continuing throughout expiration. ${ }^{16}$ Munson, et al. showed variations in respiratory pattern (peak inspiratory flow, inspiratory time and expiratory pause), with different agents. ${ }^{17}$ The typical pattern during light halothane anaesthesia was sinusoidal.
Therefore we have used a sinusoidal wave form to model spontaneous ventilation recognizing that other wave forms are possible.

Another assumption made for this model was that dead-space to tidal volume ratio $\left(V_{D} / V_{T}\right)$ is constant over a range of tidal volumes. This is warranted in view of data published by Severinghaus and Stupfel, ${ }^{18}$ Nunn and Hill ${ }^{19}$ and Hedenstierna and McCarthy. ${ }^{20}$ Contrary to what one might expect, the absolute value of physiological dead-space does not remain a constant volume but rather is best represented as a fixed percentage of tidal volume. Our management of this variable is an important difference between this study and previous ones used to evaluate circuits, where a fixed volume deadspace produced misleading frequency dependence of carbon dioxide tension. ${ }^{21}$ The value used in this study $(0.4)$ may be rather conservative and is appropriate for young normal individuals only. The constancy of $\mathrm{VD} / \mathrm{VT}$ with variable tidal volumes and frequencies has been demonstrated for healthy subjects but there is no evidence that this would apply to patients with cardiopulmonary disease and high Vo/VT values. Such patients may well have disproportionately large dead-spaces when breathing rapidly with low tidal volumes. In addition, physiological dead-space does increase with age. ${ }^{22}$ It is evident that both these factors can only cause deteriora- 
tion of gas exchange and an increase in carbon dioxide levels.

The comparison of end-tidal carbon dioxide to minute ventilation using this model with no circuit attached is virtually identical to that predicted by Nunn ${ }^{23}$ (Figure 2). When used with a Bain circuit during controlled ventilation the data obtained agrees with both Bain and Spoerel, and with Henville and Adams, showing that at high levels of minute volume, carbon dioxide tension is dependent on fresh gas flow (Figure 2). With controlled ventilation the results are also very similar to the theoretical projections of Seeley, Barnes and Conway. ${ }^{24}$ This confirms that the Bain circuit operates in the model in the same predictable fashion shown in patients during controlled ventilation.

\section{Comparison to Reference Circuits}

No essential functional difference was detectable between the Bain circuit and the Rees modification of the Ayres T-piece, when used under similar conditions at low fresh gas flows. Minor differences in construction of the two circuits (volume of the expiratory limb, and the direction of fresh gas inlet) have a negligible effect. However, recent evidence by Conway suggests that the high fresh gas flow requirements necessary to prevent rebreathing are greater for the Bain circuit $(3 \times \dot{V E})$ than for the T-piece. ${ }^{5}$

The Magill circuit (FGF $\left.=V_{E}\right)$ and $T$-piece with a high fresh gas flow $(2.5 \times \dot{V}$ E) function essentially as non-rebreathing circuits. Normocarbia is achieved at normal levels of minute ventilation.

It must be emphasized that at low levels of minute ventilation hypercarbia resuits whatever circuit is used (Figure 5). Increasing the fresh gas flow cannot compensate for hypoventilation (Figure 6).

\section{IMPLICATIONS OF REBREATHING}

Rebreathing is a feature of the Bain circuit with low fresh gas flows. The essential compensation for rebreathing is hyperpnoea. This is readily achieved with controlled ventilation but may not be easily attainable with spontaneous ventilation under anaesthesia.

The increase in end-tidal carbon dioxide due to rebreathing is represented by the difference in end-tidal carbon dioxide between the nonrebreathing circuits (Magill, high flow T-piece and no circuit) and the rebreathing Bain circuit (shaded area in Figure 5). This difference is the effective mean inspired carbon dioxide concentration, being that portion of inspired carbon dioxide which ends up in the patient's alveoli. This inspired carbon dioxide concentration increases as minute ventilation increases. Increases in minute ventilation at high levels of $\dot{V}_{\mathbf{E}}$ result only in more rebreathing and there is no fall in end-tidal carbon dioxide. Patients who attempt to compensate for an elevated carbon dioxide level by increasing ventilation succeed only in reinhaling more expired gas and their carbon dioxide levels remain on a plateau. Such increases in minute volume are therefore ineffectual with respect to gas exchange and represent an increase in the work of breathing that encroaches on the patient's respiratory reserve.

In a study by Spoerel, young, healthy, lightly anaesthetized patients, intubated for dental procedures, were able to generate high minute volumes (approx $10 \mathrm{l} / \mathrm{min}$ ). ${ }^{9}$ These patients attained acceptable levels of arterial $\mathrm{PCO}_{2}$ during anaesthesia despite trimmed fresh gas flow rates.

Unfortunately not all patients coming for anaesthesia are from such homogeneous healthy populations. Even "normal" subjects have an extremely wide variability of response to carbon dioxide and the increase in minute ventilation for every torr rise in carbon dioxide tension may vary from one to eight litres"s (i.e. some "normals" have a blunted response to carbon dioxide even when awake). In addition many studies have shown marked dose related depression of responsiveness to carbon dioxide under anaesthesia. ${ }^{26.27}$ In the face of this variability between individuals and anaesthesia-induced depression one cannot assume that all patients will increase their minute ventilation appropriately in response to carbon dioxide rebreathing. Strong surgical stimulation can increase a patient's ventilatory response to carbon dioxide under anaesthesia. ${ }^{28}$ If one relies on surgical stimulation to drive ventilation, then the gas exchange of one's patient becomes dependent on the surgeon rather than the anaesthetist.

Many patients come to anaesthesia with some degree of metabolic acidosis. The normal response is hyperpnoea with compensatory hypocarbia. The use of a rebreathing circuit may make this normal physiological response impossible, as no matter how much ventilation is increased the carbon dioxide tension will remain on a plateau.

It can be seen from Figure 8 that a patient with a $\mathrm{VD} / \mathrm{VT}$ ratio of 0.65 cannot reach normocarbia, 


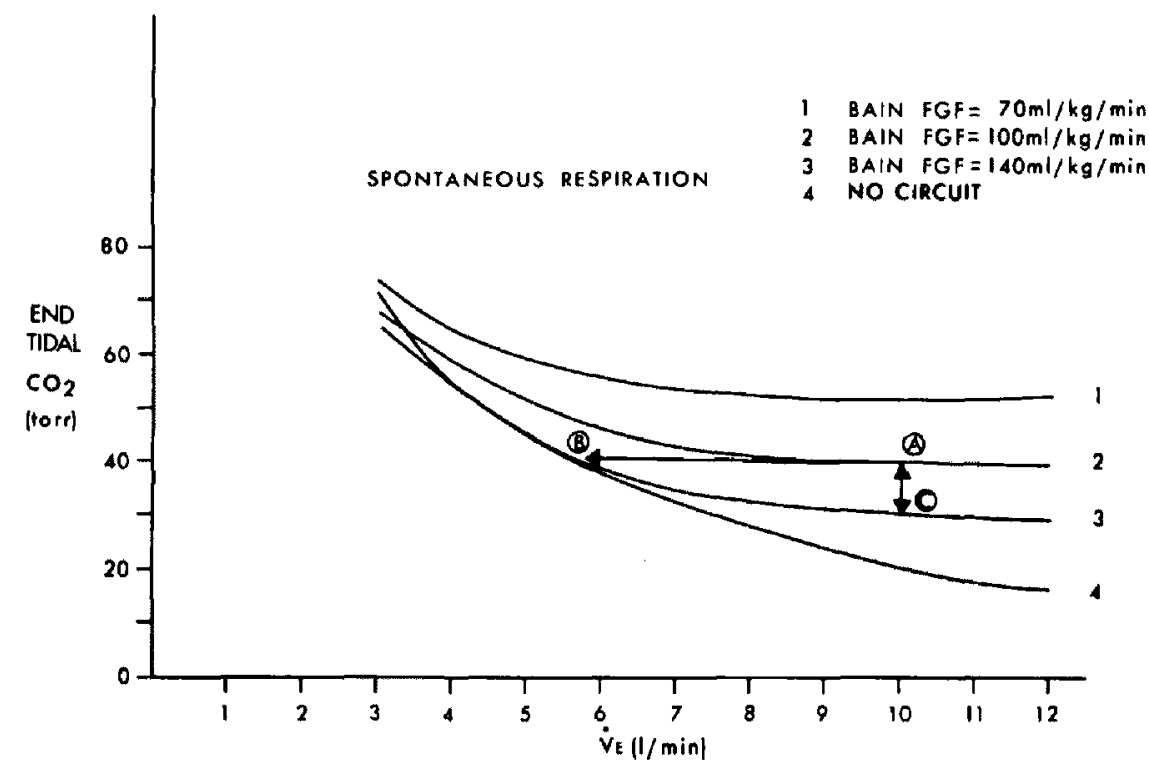

FIGURE 10. Graph showing two possible responses to an increase in fresh gas flow based on the end tidal $\mathrm{CO}_{2} /$ ventilation relationships of Figure $6\left(\hat{\mathrm{V}} \mathrm{CO}_{2}=180 \mathrm{ml} / \mathrm{min}, \mathrm{VD} / \mathrm{VT}=0.4\right)$. During spontaneous ventilation, with an increase in fresh gas flow decreasing the stimulus to respiration, movement from $A$ to $B$ is likely with a fall in $\grave{V}_{E}$ but no change in end-tidal carbon dioxide. Only when ventilation is controlled can one expect a fall in carbon dioxide from $\mathrm{A}$ to $\mathrm{C}$ as a result of an increase in fresh gas flow.

even when fresh gas flows are increased using a Bain circuit. Detailed data with mask anaesthesia are sparse in the literature but suggest that a normal $V_{D} / V_{T}$ ratio with a mask is $0.65,29$ and that minute ventilation must be high to achieve normocarbia even with a non-rebreathing circuit. ${ }^{30}$ The $V_{D} / V_{T}$ ratio is difficult to predict pre-operatively as any cardiopulmonary disease may increase the ratio. Using a Bain circuit with trimmed fresh gas flow during mask anaesthesia, a patient must compensate for both the increased dead-space and the rebreathing. We have grave concern whether patients under general anaesthesia can reach such high levels of minute ventilation, particularly with light surgical stimulation or no stimulation.

\section{Inter-Relationships of Fresh Gas Flow and Carbon Dioxide Tension}

With controlled ventilation it has been shown that carbon dioxide levels can be regulated by adjusting the fresh gas flow rate. This concept cannot be extrapolated to spontaneous ventilation because the degree of patient responsiveness to carbon dioxide is now the major determinant of $\mathrm{PaCO}_{2}$ rather than fresh gas flow. Two possible patterns of response to increased fresh gas flow are illustrated in Figure 10. With spontaneous ventilation using a rebreathing circuit point $A$ reflects an increase in $\dot{V}_{E}$ necessary to compensate for the rebreathing. If rebreathing were now decreased by increasing fresh gas flow or changing to a non-rebreathing circuit, this need for compensation would be eliminated and a decrease in minute ventilation from point $A$ to point $B$ could occur with no change in carbon dioxide level. This was clearly demonstrated by Mansell when he switched from a Bain to a Magill circuit and observed that $\mathrm{Pa}_{\mathrm{CO}_{2}}$ remained constant but minute ventilation decreased ${ }^{31}$ and has been verified repeatedly in our own experience (unpublished observations). In contrast, if the high minute ventilation present at point $A$ could be maintained, as with controlled ventilation, increasing the fresh gas flow would cause the end-tidal carbon dioxide to fall - in this example from point $A$ to point $C$, as in the study of Henville and Adams. ${ }^{2}$ It is inevitable that $\mathrm{Pa}_{\mathrm{CO}_{2}}$ and fresh gas flow inter-relationships can never be predictable as long as minute ventilation remains a variable.

\section{Efficiency of Fresh Gas Utilization}

Any reference to the efficiency of different circuits must be made with a clear definition of how this efficiency is achieved. The ideal T-piece circuit would be a non-rebreathing system, which utilized all its fresh gas to clear carbon dioxide 
and preferentially vented the alveolar gas. This would have to occur whatever the patient's respiratory variables. The Mapleson A or Magill system comes closest to this ideal during spontaneous ventilation. Its high efficiency is constant at all levels of minute ventilation (Figure 9). Because of its structure the fresh gas flow can easily be set to approximate the patient's minute ventilation without actually measuring it. Therefore a non-rebreathing system exists over a whole range of minute ventilation. Of course, the circle system with an absorber also has the same flexibility. A non-rebreathing system can be guaranteed with either a Mapleson D or E modification of the $T$-piece or a Bain circuit only if the minute ventilation is measured and the fresh gas flow set at two and a half to three times $\dot{V}$. As can be seen in Figure 9, these systems are inherently inefficient as over 75 per cent of fresh gas never reaches the patient's alveoli. If one tries to avoid this waste by decreasing fresh gas flow the penalty is rebreathing. If the fresh gas flow is determined according to body weight the $f$ value becomes highly dependent on minute ventilation. Eventually the Bain circuit (with fresh gas flow 100 $\mathrm{m} 1 / \mathrm{kg} / \mathrm{min}$ ) does achieve efficient utilization of fresh gas but only by virtue of marked hyperpnoea on the part of the patient.

Studies by Bain and Spoerel show that $\mathrm{Pa}_{\mathrm{CO}_{2}}$ attained with a fresh gas flow of $70 \mathrm{ml} / \mathrm{kg} / \mathrm{min}$ is higher in patients during spontaneous than during controlled ventilation ( 42 torr vs 35.8 torr) ( 5.59 $\mathrm{kPa}$ vs $4.76 \mathrm{kPa}$ ) despite a higher minute ventilation during spontaneous breathing (200 $\mathrm{ml} / \mathrm{kg} / \mathrm{min}$ vs $120-140 \mathrm{ml} / \mathrm{kg} / \mathrm{min}){ }^{9.32}$ A similar difference in the fractional utilization of fresh gas between spontaneous and mechanical ventilation is evident in this study. Since VD/VT was held a constant fraction (0.4) the difference in frequency between the two modes is not relevant. The $\mathrm{VCO}_{2}(180 \mathrm{ml} / \mathrm{min})$ was also the same. It is the important remaining variable of respiratory wave form which explains this difference. Since spontaneously breathing patients vary their wave forms, sometimes having expiratory pauses and at other times breathing sinusoidally, their fractional utilization of fresh gas will also vary, Therefore respiratory waveform must be considered to be one more unpredictable but significant variable of the spontaneously breathing patient that determines the carbon dioxide level achieved.

\section{CONCLUSION}

It has been demonstrated using a modified Mapleson D circuit with a lung model that levels of alveolar carbon dioxide that would be unacceptable in humans can occur with combinations of $\dot{V C O}_{2}, \dot{V E}, \mathrm{VD} / \mathrm{VT}$, and respiratory wave form, representative of values commonly encountered in anaesthetized patients. These fundamental respiratory variables are inherently unpredictable. especially in spontaneously breathing anaesthetized patients and their effects cannot be obliterated by any modification of the Mapleson D system. Recommendations for safe fresh gas flows must be set cautiously because, even with a non-rebreathing system, hypoventilation does occur. This can be corrected only with controlled ventilation. Our concern goes beyond this, when use of a rebreathing system (i.e. a Bain circuit with fresh gas flows below the Mapleson recommendations) unnecessarily introduces the possibility of hypercarbia. This additional hazard cannot be recognised easily.

It is true that trimmed fresh gas flows can be used in young healthy intubated patients free of cardiopulmonary disease who are lightly anaesthetized, with strong surgical stimulation during spontaneous ventilation. Their response is likely to be adequate and reasonable carbon dioxide levels will be maintained. Even in these cases the margin of safety will be significantly decreased. However, in any patient who has depressed response to carbon dioxide, increased physiological or apparatus dead space, elevated carbon dioxide production or restricted respiratory movement, a rebreathing circuit is unacceptably dangerous. Despite the fact that a Bain circuit at trimmed fresh gas flows may be physiologically tolerable in some, that in itself does not justify the introduction of a potential hazard which can be readily avoided by simply using another circuit.

\section{SUMMARY}

A lung model was used to simulate gas exchange for a $70 \mathrm{~kg}$ adult under anaesthesia. It was demonstrated that the modified Mapleson D circuit (Bain) with low fresh gas flows determined according to body weight is a partial rebreathing system. With controlled ventilation this can be compensated for by increasing minute ventilation above the predicted and the arterial carbon dioxide level can then be regulated by adjusting the fresh gas flow. During spontaneous ventilation this compensation is critically dependent on the patient's ability to increase minute ventilation. Therefore in any particular case the arterial carbon dioxide is unpredictable and totally dependent on carbon dioxide responsiveness, carbon dioxide production, physiological dead- 
space, respiratory wave form, and apparatus dead-space. Although normocarbia can be achieved by certain ideal patients despite low fresh gas flows it can be done only if minute ventilation is markedly increased. This enforced hyperpnoea will significantly encroach on the respiratory reserve of these patients and may well be unattainable in some. We conclude that any decrease in respiratory drive, increase in carbon dioxide production, increase in physiological or apparatus dead-space (i.e. a mask) will produce potentially dangerous hypercarbia using a Bain circuit with a fresh gas flow of $100 \mathrm{ml} / \mathrm{kg} /$ minute. This hazard is not easily recognized. The only way to minimize these factors during spontaneous ventilation is by the use of a non-rebreathing circuit. To do this with a T-piece or Bain circuit the fresh gas flow must be between 200 and 300 $\mathrm{ml} / \mathrm{kg} / \mathrm{min}$ for an average adult, with this requirement being highly dependent on all the variables outlined. One must decide whether the low economy and high level of operating room pollution with this wide range of flow outweigh the advantages of trying to make the Mapleson D a universal circuit.

\section{RÉSUmÉ}

Un modèle a été employé pour simuler les échanges gazeux d'un adulte de $70 \mathrm{~kg}$. On a déjà démontré qu'en circuit Mapleson D modifié ou circuit Bain alimenté par des gaz frais à bas débits estimés selon le poids du malade se comportait comme un système à rebreathing partiel. En ventilation contrôlée, l'augmentation de la ventilation au-delà de la valeur prédite compense et c'est le débit de gaz frais détermine la $\mathrm{PCO}_{2}$ artérielle. En ventilation spontanée, cette compensation dépend essentiellement de l'habileté du malade à hyperventiler. En ventilation spontanée, il est donc impossible de prédire la $\mathrm{PCO}_{2}$ artérielle dépendant maintenant de la capacité de réponse à la stimulation du $\mathrm{CO}_{2}$ et de sa production, de l'espace mort physiologique, des caractéristiques du cycle respiratoire et de l'espace mort du montage. On peut quelquefois maintenir la normocarbie avec des débits peu élevés de gaz frais mais ceci nécessite une augmentation importante de la ventilation. L'hyperpnée nécessaire sera possible pour les sujets ayant des réserves respiratoires suffisantes et impossible pour les autres. Les auteurs en concluent que la perte du stimulus respiratoire, l'augmentation de la production de gaz carbonique et de l'espace mort physiologique ou mécanique (par exemple, celle causée par un masque) produiront une hypercarbie qui peut s'avérer dangereuse lorsqu'on utilise le circuit Bain avec une alimentation en gaz frais de l'ordre de $100 \mathrm{ml} / \mathrm{kg} / \mathrm{min}$. C'est là un danger qui risque de passer inaperçu. Le seul moyen d'éviter ce danger pendant la ventilation spontanée est d'utiliser un circuit sans rebreathing. Avec une tube en T ou sur circuit Bain, le débit de gaz frais doit se situer entre 200 et $300 \mathrm{ml} / \mathrm{kg} / \mathrm{min}$ pour un adulte moyen tout en tenant compte des facteurs déjà mentionnés. A chacun de décider si les avantages obtenus en faisant du circuit Mapleson D un circuit universel seront annulés par son coût élevé d'opération et le haut degré de pollution causés par de tels débits.

\section{ACKNOWLEDGEMENTS}

The authors wish to thank Mr. George Volgyesi for his technical assistance and Dr. A.C. Bryan and Dr. D.J. Steward for their advice and criticism.

\section{REFERENCES}

I. Bain, J.A. \& Spoerel, W.E. A streamlined anaesthetic system. Canad. Anaesth. Soc. J. 19: 426 (1972).

2. Henville, J.D. \& Adams, A.P. The Bain anaesthetic system. Anaesthesia 31:247 (1976).

3. CHU, Y.K. RaH, K.H. \& BOYAN, C.P. Is the Bain circuit the future anaesthesia system? An evaluation. Anesthesia and Analgesia. Current Researches 56: 84 (1977).

4. MAPLesON, W.W. The elimination of rebreathing in various anaesthetic systems. Brit. J. Anaesth. 26: 323 (1954).

5. Conway, C.M., Seeley, H.F., \& Barnes, P.K. Spontaneous ventilation with a Bain anaesthetic system. Brit. J. Anaesth. 49: 1245(1977).

6. UNGERER, M.J. A comparison between the Bain and Magill systems during spontaneous breathing. Canad. Anaesth. Soc. J. 25: 122 (1978).

7. Grey, T.C. \& NUnN, J.F. General Anaesthesia, 3rd ed. London, Butterworth (1971).

8. HARRISON, G.A. The effect of the respiratory flow pattern on rebreathing in a T-piece system. Brit. J. Anaesth. 36: 206 (1964).

9. Spoerel, W.E., Aitken, R.R., \& Bain, J.A. Spontaneous respiration with the Bain breathing circuit. Canad. Anaesth. Soc. J. 25: 30 (1978).

10. WEST, J.B. Respiratory physiology - the essentials, ist ed., Baltimore: Williams and Wilkins (1975).

11. CONWAY, C.M. Alveolar gas relationships during use of semi-closed rebreathing anaesthetic systems. Brit. J. Anaesth. 48: 865 (1976).

12. NunN, J.F. Prediction of carbon dioxide during anae sthesia. Anaesthesia /5: 123 (1960).

13. Ramanathan, S., Chalon, J., Capan, L., Patel, C., \& TuRndorf, H. Rebreathing char- 
acteristics of the Bain anaesthesia circuit. Anesth. Analg. 56: 822 (1978).

14. KeEnaN, R.L. \& BOYNaN, C.P. How rebreathing anaesthetic systems control $\mathrm{Pa}_{\mathrm{CO}_{2}}$ : studies with a mechanical and mathematical model. Canad. Anaesth. Soc. J. 25: 117 (1978).

15. NUNN, J.F. \& Ezı-ASHI, T.I. The accuracy of respirometer and ventigrator. Brit. J. Anaesth. 34 : 422 (1962)

16. WILlis, B.A., PENDER, J.W., \& MAPLeson, W.W. Rebreathing in a T-piece: volunteer and theoretical studies of the Jackson-Rees modification of Ayre's T-piece during spontaneous respiration. Brit. J. Anaesth. 47: 1239 (1975).

17. MUnSon, E.S., FarnhaM, M., \& Hamilton, W.K. Studies of respiratory gas flows. A comparison using different anaesthetic agents. Anesthesiology 24: 61 (1963).

18. Severinghaus, J.W. \& Stupfel, M. Alveolar dead space as an index of distribution of blood flow in pulmonary capillaries. J. Appl. Physiol. 10: 335 (1957).

19. NUNN, J.F. \& HILL, D.W. Respiratory dead space and arterial to end-tidal $\mathrm{CO}_{2}$ tension difference in anesthetized man. J. Appl. Physiol. 15: 583 (1960).

20. Hedenstierna, S. \& McCarthy, G. The effect of anaesthesia and intermittent positive pressure ventilation with different frequencies on the anatomi$\mathrm{cal}$ and alveolar deadspace. Brit. J. Anaesth. 47: 847 (1975).

21. INKSTER, J.S. The T-piece technique in anaesthe sia. Brit. J. Anaesth. 28: 512 (1956).

22. Bates, D.V., MACKLEM, P.T., \& Christie, R.V. Respiratory function in disease. 2 nd ed. Philadelphia: Saunders (1971).

23. NUnN, J.F. Applied Respiratory Physiology, Ist ed. London: Butterworth (1969).
24. Seeley, H.F., Barnes, P.K., \& Conway, C.M. Controlled ventilation with Mapleson D system, a theoretical and experimental study. Brit. J. Anaesth. 49: 107 (1977).

25. Pengelly, L.D., Rebuck, A.S., \& Campbell, E.J.M. Loaded Breathing, Ist ed. Toronto: Longman (1974).

26. Munson, E.S., Larson, P.C., Babad, A.A., ReGan, M.J., Beuchel, D.R., \& Eger, E. II. The effects of halothane, furoxene and cyclopropane on ventilation: a comparative study in man. Anesthesiology 27: 716 (1966).

27. Larson, C.P., Eger, E. Il, Muallem, M., Buechel, D.R., Munson, E.S., \& Eisele, J.H. The effects of diethyl ether and methoxyflurane on ventilation: II. a comparative study in man. Anesthesiology 30: 714 (1969).

28. Eger, E. Il, Dolan, W.M., Stevens, W.C., MilLER, R.D., \& WAY, W.L. Surgical stimulation antagonizes the respiratory depression produced by forane. Anesthesiology 36:544 (1972).

29. KaIN, M.L., Panday, J., \& NUNN, J.F. The effect of intubation on dead space during halothane anaesthesia. Brit. J. Anaesth. 41:94(1969).

30. BLACK, G.W. \& MCKANE, R.V. Respiratory and metabolic changes during methoxyflurane and halothane anaesthesia. Brit. J. Anaesth. 37: 409 (1965).

31. MANSELL, W.H. Spontaneous breathing with the Bain circuit at low fiow rates: a case report. Canad. Anaesth. Soc. J. 23: 432 (1976).

32. BAin. J.A. \& SPOEREL, W.E. Flow requirements for a modified Mapleson D system during controlled ventilation. Canad. Anaesth. Soc. J. 20: 629 (1973). 